\title{
Regional Variations of the w-upper Bound Magnitude of GIII Distribution in the Iranian Plateau
}

\author{
Hiwa MOHAMMADI ${ }^{1}$ and Yusuf BAYRAK ${ }^{2}$ \\ ${ }^{1}$ Department of Earth Sciences, College of Sciences, Shiraz University, Shiraz, Iran \\ e-mail: Hiwa.2006.waran@gmail.com (corresponding author) \\ ${ }^{2}$ Agri Ibrahim Çeçen University, Agri, Turkey; e-mail: ybayrak@agri.edu.tr
}

\begin{abstract}
The Iranian Plateau does not appear to be a single crustal block, but an assemblage of zones comprising the Alborz-Azerbaijan, Zagros, Kopeh-Dagh, Makran, and Central and East Iran. The Gumbel's III asymptotic distribution method (GIII) and maximum magnitude expected by Kijko-Sellevoll method is applied in order to check the potentiality of the each seismogenic zone in the Iranian Plateau for the future occurrence of maximum magnitude $\left(M_{\max }\right)$. For this purpose, a homogeneous and complete seismicity database of the instrumental period during 19002012 is used in 29 seismogenic zones of the examined region. The spatial mapping of hazard parameters (upper bound magnitude $(\omega)$, most probable earthquake magnitude in next 100 years $\left(M_{100}\right)$ and maximum magnitude expected by maximum magnitude estimated by Kijko-Sellevoll method $\left(M_{\max }^{K-S}\right)$ reveals that Central and East Iran, Alborz and Azerbaijan, Kopeh-Dagh and SE Zagros are a dangerous place for the next occurrence of a large earthquake.
\end{abstract}

Key words: Iranian Plateau, maximum magnitude, Gumbel's III asymptotic distribution, most probable earthquake magnitude in next 100 years $\left(M_{100}\right)$, maximum magnitude expected by Kijko-Sellevoll method.

Ownership: Institute of Geophysics, Polish Academy of Sciences;

(C) 2016 Mohammadi and Bayrak. This is an open access article distributed under the Creative Commons Attribution-NonCommercial-NoDerivs license,

http://creativecommons.org/licenses/by-nc-nd/3.0/. 


\section{INTRODUCTION}

Tectonically, the Iranian Plateau is located in the main part of the AlpineHimalayan orogenic belt; therefore, it is one of the most highly seismic regions of the world. Many destructive earthquakes in the last century confirm the high seismicity of Iran. As a result, the need for more accurate seismic hazard studies in the region has become progressively more important for earthquake engineering applications. Statistical methods are useful for characterizing seismic hazard because earthquakes are, for all practical purposes, random phenomena. Statistical analysis complements the deterministic approach to seismic hazard assessment and provides a tool for decision making in matters of resource allocation and public policy (Dargahi-Noubary 2002). Several statistical methodologies and models have been emphasized and being used in different regions of the world to estimate earthquake hazard parameters like expected maximum magnitude, $b$-value of Gutenberg-Richter relationship, activity rate, upper bound magnitude $(\omega)$, and modal values among others (Tinti and Mulargia 1985, Kijko and Sellevoll 1989, 1992; Pisarenko et al. 1996, Tsapanos et al. 2002, Tsapanos 2003, Tsapanos and Christova 2003, Kijko 2004, Wheeler 2009, Mueller 2010, Kijko and Singh 2011, Yadav et al. 2010a, b; 2012a, b).

The most common seismic parameter analyzed is the magnitude of the earthquakes. Probabilistic methods are commonly used to compute or forecast the expectation of different magnitudes in an area. In seismic hazard assessment, three types of maximum magnitudes are considered viz. maximum historic magnitude, maximum credible magnitude and maximum regional magnitude (Reiter 1990). The maximum historic magnitude is the maximum magnitude which has historical or instrumental confirmation of occurrence in any seismogenic source or fault region and it is lower bound to the maximum size. The maximum credible magnitude is obtained by the reasonable assessment of maximum earthquake potential with respect to the ambient tectonic regime. It does not show actual occurrence and it is less than the maximum regional magnitude but larger or equal to the maximum historic magnitude. The maximum regional magnitude, also called maximum possible magnitude in probabilistic analysis, is the absolute though improbable upper bound magnitude of earthquake size determined by earthquake processes that will occur in a certain time period and a given source region. There is no unique method to estimate maximum magnitude. However, there are two techniques to estimate it, i.e., deterministic and probabilistic (Kijko and Sellevoll 1989, 1992; Field et al. 1999, Koravos et al. 2003, Kijko 2004, Mueller 2010, Kijko and Singh 2011). Kijko and Sellevoll $(1989,1992)$ and Kijko (2004) introduced a new approach based on maximum likelihood estimation method to estimate maximum magnitude using historical and in- 
strumental data. The rank ordering statistic of extreme values is applied by Sornette et al. (1996) to the distribution of large earthquakes for extracting the tail of the distribution of sparse data sets. Krinitzsky (2002) proposed the definition of some maximum magnitudes appropriate for use in engineering design. Seismic moment upper bound is considered by Kagan (2002) in order to discuss various theoretical distributions that can be used to approximate the seismic moment data. The Gumbel's third asymptotic distribution of extreme values (GIII) has also proved useful in estimating upper bound magnitude in different regions of the world (Makropoulos 1978, Burton 1979, Makropoulos and Burton 1983, Tsapanos and Burton 1991, Tsapanos 1997, Bayrak et al. 2008, Yadav et al. 2012b, 2013; Tsapanos et al. 2014).

The theory of extreme values described by Gumbel (1958) has the advantage that it does not require analysis of the complete record of earthquake occurrence, but uses the sequence of earthquakes constructed from the largest values of magnitude over a set of predetermined intervals. Both first and third asymptotic distributions of extreme value have been proved useful in mapping seismic hazard (Nordquist 1945, Epstein and Lomnitz 1966, Yegulalp and Kuo 1974, Knopoff and Kagan 1977, Burton 1977, Makropoulos 1978, Makropoulos and Burton 1986, Tsapanos and Burton 1991, Bayrak et al. 2008, among others). The advantage of Gumbel's third asymptotic distribution (GIII) over first distribution (GI) is that it includes a parameter known as upper-bound magnitude $(\omega)$. The $\omega$ value is directly related with the finite maximum stress which can be stored and released as an earthquake by the rocks of a region (Tsapanos and Burton 1991, Tsapanos 1997). Thus, for calculation of the occurrence or expectation of extreme magnitude earthquakes using probabilistic models, the GIII distribution allows an appropriate and natural physical interpretation. On the other hand, there are different opinions on the use of the GIII distribution for seismicity assessment. Kaila and Narain (1971) suggested that, since GIII mainly involves great earthquakes, it is not an ideal criterion for seismicity parameters assessment. However, Båth $(1975,1983)$ denoted that the dependency of the method on large events is of important advantage, given that the magnitudes of large earthquakes are more accurately determined than those of small events. Thus for estimation of the occurrence or expectation of extreme magnitude earthquakes using probabilistic models, the GIII allows an appropriate and natural physical interpretation.

Burton (1979) applied this methodology in southern Europe through India to estimate earthquake hazard parameters. Tsapanos and Burton (1991) estimated earthquake hazard parameters using this method for some specific regions of the world and prepared contour maps of most probable maximum magnitudes in next 85 years. Later, Tsapanos (1997) evaluated upper-bound magnitudes in the subduction zones of the Circum-Pacific region. Bayrak et 
al. (2008) used this method for 24 seismogenic regions in Turkey and surroundings to estimate upper-bound magnitude. Yadav et al. (2012b) applied this method in 28 seismogenic regions in the Hindukush-Pamir Himalaya to estimate upper-bound magnitude and 100-years magnitude. Yadav et al. (2013), by using this method, prepared contour maps of most probable maximum magnitudes in the Hindukush-Pamir Himalaya and adjacent regions in annual and next 100 years. Recently Tsapanos et al. (2014) prepared contour maps of most probable maximum magnitudes using this method in the Turkey and its vicinity in annual and next 50 years.

In this study, we have applied GIII distribution in the Iranian Plateau to assess the earthquake hazards in terms of upper bound magnitude $(\omega)$ and possible earthquake magnitude that can occur in next 100 years $\left(M_{100}\right)$. Furthermore, we have computed the maximum earthquake magnitudes $\left(M_{\max }^{K-S}\right)$ from Kijko-Sellevoll method to correlate and compare $\omega$ values with $M_{\max }^{K-S}$ values for these source zones. The results of this study will be useful to produce a brief atlas to characterize the earthquake hazard.

\section{TECTONICS}

The spatial distribution and magnitude of earthquakes in different regions of the Iranian Plateau are not similar. This is primarily a result of Iran's position in a 1000-km wide zone of compression between the colliding Eurasian and Arabian continents (Engdahl et al. 2006) and its location between the Arabian Plate in the south and southwest and the Indian Plate in the east.

Iran does not appear to be a single crustal block, and the distribution of active deformation is not uniform (Fig. 1). The shortening is thought to be concentrated in these main active belts of Zagros, Kopeh-Dagh, AlborzAzerbaijan, and Central and East Iran (Talebian and Jackson 2004). Based on the global positioning system (GPS), Vernant et al. (2004) indicated the rate of deformation of the Iranian Plateau from less than $2 \mathrm{~mm} / \mathrm{yr}$ in Central and East Iran to $19.5 \pm 2 \mathrm{~mm} / \mathrm{yr}$ in the Makran subduction zone.

Continental-continental collision zone of Zagros in southwest Iran is one the youngest and most active continental collision zone on the earth (Snyder and Barazangi 1986). Seismicity in the Zagros belt is restricted to the region between the main Zagros Thrust and the Persian Gulf. Most of the larger earthquakes occur on high-angle reverse planes that strike parallel to the trend of the fold axes (Jackson and McKenzie 1984). Strong earthquakes are thought to occur on blind active thrust faults that do not reach the surface (Berberian 1995). There is considerable uncertainty about their extent, geometry and the mechanism (Mirzaei et al. 1999). Berberian (1983) state that Zagros absorbed a major part of the Arabia-Persia regional shortening by thrust faulting. 


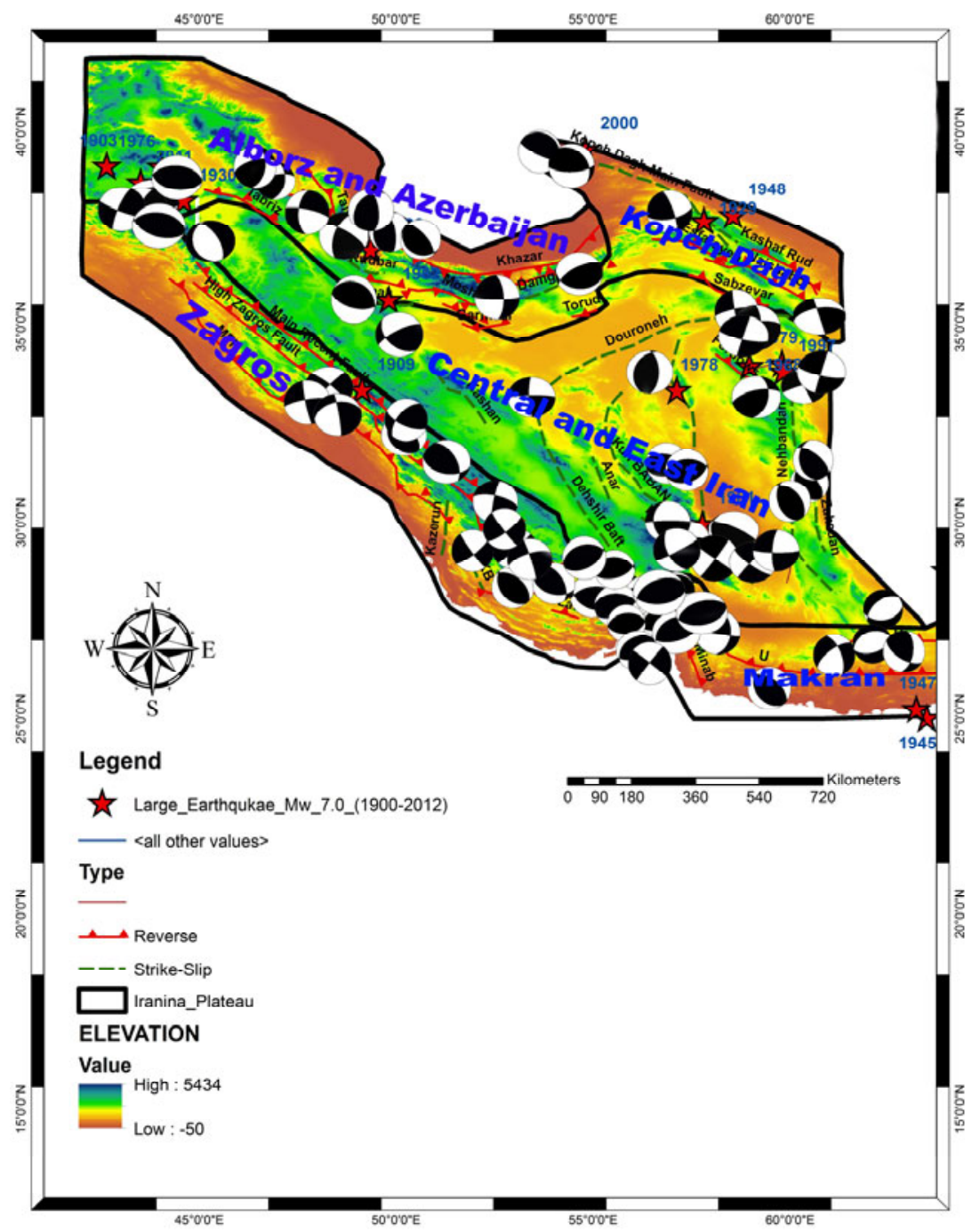

Fig. 1. Tectonic map of the Iranian Plateau showing the major active faults (modified from Berberian (2014)). Focal mechanism solutions of earthquakes with $M w \geq 5.8$ obtained by Harvard GCMT catalogue during 1976-2012 are also shown. The large and damaging earthquakes with $M w \geq 7.0$ that occurred during 19002012 are shown with stars along with the year of occurrence.

The highly seismic region of Iran is Alborz-Azerbaijan covering north and northwest of Iran. Jackson et al. (2002) reported that reliable earthquake depths in the Alborz are above $15 \mathrm{~km}$ and that most focal mechanisms present left-lateral strike-slip motions along the faults parallel to the regional 
strike of the range and reverse faulting. This seismotectonic province has experienced a severe seismicity during the last century. The Alborz is a stack of thrust sheets, produced by late Cenozoic compressional deformation (Alavi 1996). Exposed thrusts with the greatest throw generally occur in the south of the Alborz. Prominent left-lateral strike-slip faults occur along the length of the Alborz, trending parallel to the thrusts and folds in each region. Structures at both the eastern and western ends of the Alborz change in strike to pass into adjacent fold and thrust belts: the Talesh in the west and the Kopeh-Dagh in the east (Berberian 1997). All faults in the Alborz are parallel to the range and participate in its shortening (Allen et al. 2003). Azerbaijan sub-province is a complex tectonic system trapped between Arabia, Anatolia, and Eurasia. One of the most important fault systems in this zone is the North Tabriz Fault system (Berberian and Yeats 2001, Allen et al. 2003).

The continental collision zone of Kopeh-Dagh in the northeast shows a northern segment of the Alpine-Himalayan orogenic belt. The characteristic of Kopeh-Dagh seismic activity is the relative frequency of great earthquakes with low depth. In the Kopeh-Dagh, crustal shortening has been taking place in a belt of up to $200-300 \mathrm{~km}$ wide as a result of compressional motion of the Central Iran Block against the stable plates of Turkemenistan and Afghanistan. This seismically active area mainly accommodated along a large intra-continental fault system, Ashkabad fault zone (Shabanian et al. 2009). Hollingsworth et al. (2006, 2007) believe that Kopeh-Dagh central part is an array of active right-lateral strike-slip faults (e.g., Quchan fault system), that obliquely affects the mountain range and produce several kilometers offsets in geomorphology. These right-lateral faults are thought to have slipped in major destructive earthquakes during the 19th and 20th centuries.

The Makran Mountains in the southeast are a continuation of the southern arc of the Alpine orogenic system, from the vicinity of Bandar Abbas to West Pakistan. The oceanic-continental subduction zone of Makran, where the consumption of oceanic crust of Arabian plate has occurred continuously since the early Cretaceous along a north dipping subduction zone underneath the Eurasia-Central Iranian microcontinent, covers the southeast of the Iran (Mirzaei et al. 1999). The large magnitude events are associated to the down-going plate at the intermediate depths or to the superficial large historical earthquakes in the eastern Makran (Byrne et al. 1992).

The Central and East Iranian Block is being compressed between two plates of greater rigidity, Arabia and Eurasia. The Central and East Iranian Block is characterized by discontinuous seismic activity with shallow, large magnitude earthquakes with apparent long recurrence periods (Berberian et al. 2000). At the low elevation and apparent lack of seismicity in the Dasht- 
e-Lut suggest that the Lut Block is a relatively rigid block within this distributed deforming zone. Some of the roughly N-S right-lateral shear between Central and East Iranian Block and Afghanistan, which is effectively part of stable Eurasia, occurs on the long N-S strike slip faults of Sistan near the Iran-Afghan border (Berberian et al. 2000). This block is bordered by the Zagros folded belt in the southwest, the Alborz Mountains in the north, the Kopeh-Dagh Mountains in the northeast, and several strike-slip faults in the east. Several earthquakes are associated with surface faulting in this region. The seismically active area of eastern Iran characterized by long rightlateral strike-slip major faults. Walker et al. (2004) and also Walker and Jackson (2004) suggested a total of $100 \mathrm{~km}$ right lateral shear between Iran and Afghanistan. The northward motion of central Iran relative to western Afghanistan is accommodated by right-lateral shear across the eastern Iran, on N-S right-lateral strike-slip faults that surround the Dasht-e Lut (e.g., Walker and Jackson 2004, Meyer and Le Dortz 2007). The general features of the present-day tectonics in the arid and sparsely populated region of eastern Iran are broadly understood (e.g., Berberian 1976, 1977; Jackson and McKenzie 1984, Berberian and Yeats 1999). Also major active strike-slip and thrust faults are observed in several zones (Walker et al. 2004)

\section{DATA USED AND SOURCE ZONATION}

We used an earthquake catalogue extending from 1900 to 2012. The Institute of Geophysics, University of Tehran (IGUT) compiled a catalogue including prehistoric, historical and instrumental earthquakes of Iran and adjacent areas until 2000 A.D. It is based on Ambraseys and Melville (1982), Berberian (1994), the International Seismological Centre and the US Geological Survey (USGS). We used the catalogue by IGUT from 1900 to 2000 and extended it to 2012 with the help of data provided by the USGS. The compiled catalogue has been homogenized with respect to the moment magnitude scale $(M w)$ using different empirical regression relationships developed by Karimiparidari et al. (2013) between body-wave $(\mathrm{mb})$, surface-wave $(M s)$ and local magnitude $(M L)$. The homogeneous catalogue contains 5436 earthquakes with magnitude $M w \geq 4$ between 1900 and 2012. The locations are illustrated in Fig. 2. By using the method of Uhrhammer (1986), dependent events (foreshocks and aftershocks) have been removed. In this method, a scan for the entire catalogue has been performed within a defined spatial and temporal window for each given earthquake. All events (foreshocks and aftershocks) with epicenters falling within the defined two windows are removed. In total, $32.08 \%$ of the events in the primary catalogue have been eliminated after filtering out foreshocks and aftershocks and the declustered catalogue contains 3692 independent earthquakes with $M w \geq 4$. The com- 


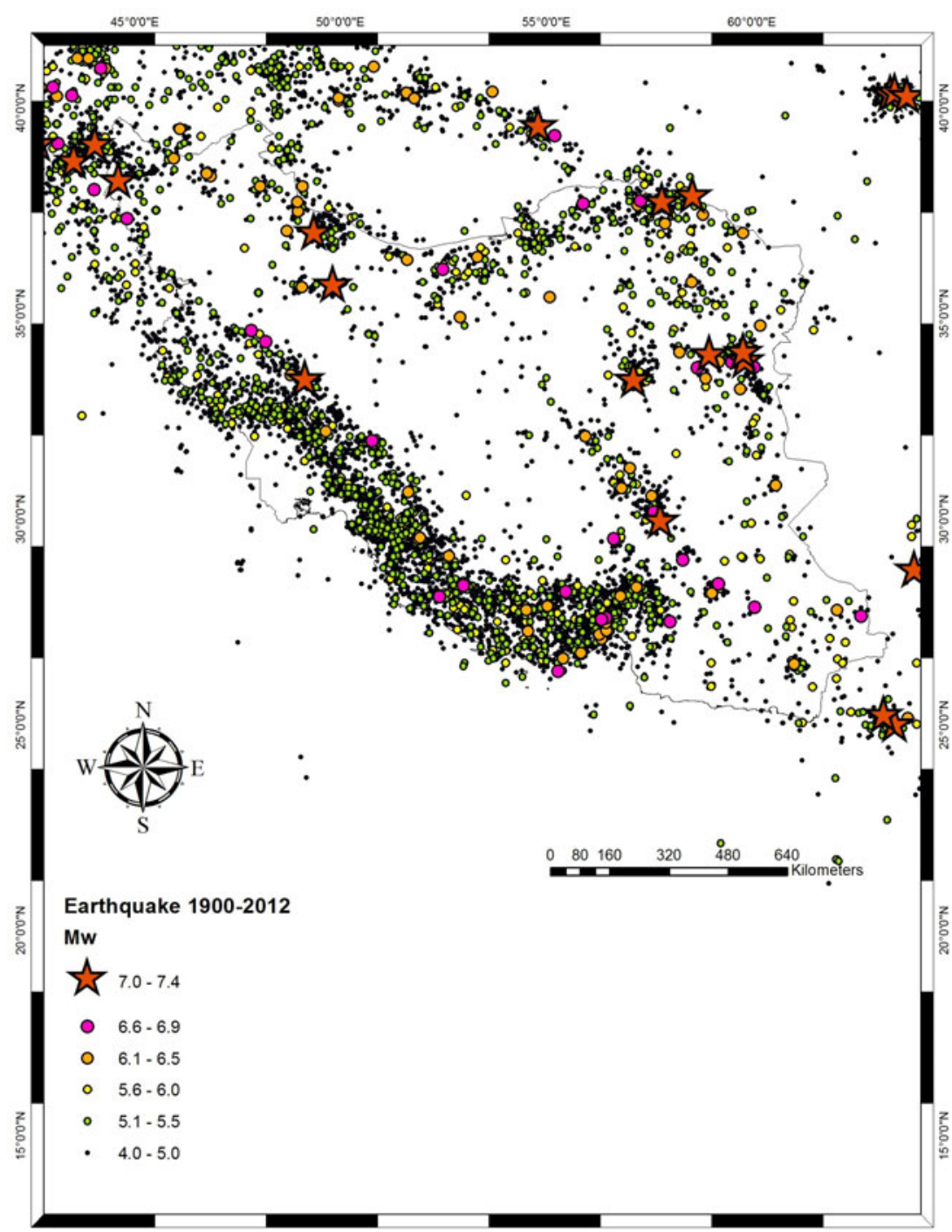

Fig. 2. The epicentral distribution of earthquakes of $M w \geq 4.0$ occurred during the period 1900-2012.

pleteness of earthquake catalogue has been performed with respect to magnitude and time. The magnitude of completeness $(M c)$, also called threshold or cut-off magnitude is defined as the lowest magnitude at which $100 \%$ of events in space-time volume are detected. The methods of Entire Magnitude Range (EMR) and Maximum Curvature (Wiemer and Wyss 2000) have been used to estimate $M c$ that is equal to 4.5. We have also estimated $M c$ for each 
and every seismogenic zones in the considered region, keeping in mind that $M c$ varies spatially in a wider region.

The seismotectonic province is considered to be an area that under the present-day geodynamic regimes has a comparable tectonic setting and unified seismicity pattern (Ye et al. 1995). Also, it can be defined as a geographic region of some geological, geophysical, and seismological similarity with the assumption of uniform earthquake potential (Tavakoli and GhaforyAshtiany 1999). Until now, the several suggestions (e.g., Stoklin 1968, Takin 1972, Berberian 1976, Nowroozi 1976, Nogol-Sadat 1994, Tavakoli 1996, Mirzaei et al. 1998, Zare 2010) offered for seismotectonic zonation of Iran were partly based on expert opinions, as well as field data. Recently, Karimiparidari et al. (2011) proposed 29 seismotectonic provinces with different specification. They used seismicity catalogue, active fault maps, magnetic intensity map, and topography data to determine the borders of each zone.

\section{THE APPLIED METHODS}

In the present study, an assessment of the maximum magnitude or upper bound magnitude is based on the two methods: (a) Gumbel's third asymptotic distribution of extreme values method (GIII), and (b) Kijko-Sellevoll method of maximum likelihood estimate (Kijko and Sellevoll 1989, 1992; Kijko 2004).

\subsection{Gumbel's third asymptotic distribution (GIII)}

In order to analyse earthquake hazard in the Iranian Plateau we shall pursue the method of particular interest for earthquake hazard evaluation, which is the Gumbel's third asymptotic distribution of extremes (GIII). The method needs only the largest earthquake magnitudes occurring in each of a set of predetermined equal time intervals (of 1, 2, 3, etc. years) and is satisfied only for the data of the recent catalogues (Yegulalp and Kuo 1974). A most often observation is the absence of data in some of the equal-time selected. These are called "missing years". Burton (1977) suggested that as a rule-ofthumb, if these missing entries are less or equal to $25 \%$, the assessed parameters may be estimated without any noticeable loss of accuracy.

Let $M i$ (with $i=1,2,3, \ldots, n$ ) be the largest earthquake magnitudes observed in successive equal-time intervals for a given area. The probability that $M$ is an extreme value of the magnitude is given by the cumulative distribution function:

$$
P(M)=\exp \left[\left(\frac{\omega-M}{\omega-u}\right)^{k}\right],
$$


where $\omega$ is the upper bound to $M, k$ is the shape parameter, and $u$ is the characteristic value with $P(u)=1 / e$ and $P(\omega)=1$. The three parameters allow for curvature through the shape or curvature parameter $k$.

In general, we have extreme intervals of $N$ year duration and the corresponding distribution of $P_{M}(M)$ is associated to one year extremes of $P_{1}(M)$ by the relation derived by Burton (1977):

$$
\sqrt[N]{P_{N}(M)}=P_{1}(M) .
$$

Equation 3 has been introduced in seismic hazard by Burton (1977). The largest annual earthquake magnitudes $\left(M_{1}, M_{2}, M_{3}, \ldots, M_{N}\right)$ are selected from seismic event catalogue of time span of $N$ years and arranged in increasing size. Gringorten (1963) suggested different plotting point values:

$$
P(M)=\frac{(i-0.44)}{N+0.12}
$$

and points out that this equation is more convenient for plotting rule use because it gives a better fit at high magnitudes and long return periods of interest and so is adopted for GIII (Burton 1979). Equation 3 is adopted for the present study.

For curve fitting purposes, Eq. 1 is firstly transposed to

$$
M=\omega-(\omega-u)[-\ln (P(M))]^{\lambda},
$$

where $\lambda=1 / k$ and plotting $M$ as ordinate and $(-\ln (P(M)))^{\lambda}$ as abscissa draws a straight line with $\omega$ as intercept and $-(\omega-u)$ as slope. Equation 4 is nonlinear and the adopted curve fitting process is described in details by Burton (1979).

Moreover, the most probable magnitude for a time period of $T$ years (Burton 1977) is given by:

$$
R M=\omega-(\omega-u)\left[\frac{1-\lambda}{T}\right]^{\lambda} .
$$

\subsection{Kijko-Sellevoll method of maximum likelihood estimate}

In this study, also we used the approach of Kijko and Sellevoll $(1989,1992)$ and Kijko (2004) to calculate maximum regional magnitude $M_{\max }$ in 29 seismogenic zones of the Iranian Plateau. Kijko and Sellevoll (1989, 1992) have developed an approach which permits the calculation of maximum likelihood estimates of the parameters related to earthquake hazard. It accommodates the "gaps" in both historical and instrumental parts of the catalogue. It allows the combination between earthquakes of historical epochs and those which are instrumental data of short period. 
The probability that $n$ earthquakes will occur in $T$ years can be calculated assuming that the earthquake occurrence is a Poisson process:

$$
P(n)=\frac{\exp (\lambda T)(\lambda T)^{n}}{n !},
$$

where $\lambda$ is the number of occurrences of earthquakes with magnitude greater than or equal to threshold magnitude $\left(M_{\min }\right)$. Estimation of $M_{\max }$ is based on the equation that compares the largest observed magnitude ( $\left.M_{\max }^{\mathrm{obs}}\right)$ and the maximum expected magnitude $E\left(M_{\max } / T\right)$ during the time span of "T" of catalogue (Kijko 1988, 2004). Following the supposition that earthquake magnitudes are distributed according to the double truncated GutenbergRichter relation, the estimator of maximum regional magnitude $M_{\max }$ takes the following form (Kijko 1988):

$$
M_{\text {max }}=M_{\text {max }}^{\mathrm{obs}}+\frac{E_{1}\left(T z_{2}\right)-E_{1}\left(T z_{1}\right)}{\beta \exp \left(-T z_{2}\right)}+M_{\text {min }} \exp (-\lambda T) .
$$

It is not difficult to show that the appropriate variance of the regional maximum magnitude $\left(M_{\max }\right)$ estimated according to Eq. 6 is equal to that derived by Kijko (2004):

$$
\operatorname{Var}\left(M_{\text {max }}\right)=\sigma_{M}^{2}+\left[\frac{E_{1}\left(T z_{2}\right)-E_{1}\left(T z_{1}\right)}{\beta \exp \left(-T z_{2}\right)}+M_{\text {min }} \exp (-\lambda T)\right]^{2},
$$

where it is assumed that the observed magnitude is distorted by an observational error, which is distributed normally with a known standard deviation $\sigma_{M}^{2}$ (Kijko and Dessokey 1987).

\section{RESULTS AND DISCUSSION}

The aim of this study is the assessment of earthquake hazard parameters of the Iranian Plateau. For this purpose, we used the computer program HAZAN with many alterations, compiled by Makropoulos and Burton (1986). During a time span of 112 years (1900-2012) a number of successive large earthquakes (with $M \geq 7.0$ ) occurred in the Iranian Plateau. In GIII distribution method, a sequence of earthquakes with largest magnitude in a set of predetermined equal-time interval was analyzed rather than the whole dataset.

In Table 1 we listed the values of $\omega, u$, and $\lambda$, with their uncertainty as they are estimated through Gumbel's III technique. The maximum observed magnitude ( $M_{\max }^{\mathrm{obs}}$ ), recorded during instrumental time, according to the catalogue used, and difference $\left(\omega-M_{\max }^{\mathrm{obs}}\right)$ are also listed in Table 1. The maxi- 


\section{Table 1}

The estimated values of $\omega, u, \lambda$ and their standard deviations, probable earthquake magnitude in the next 100 years $\left(M_{100}\right)$ and its standard deviation, extreme years $(k)$, maximum magnitude estimated by Kijko-Sellevoll method $\left(M_{\max }^{K-S}\right)$ and its standard deviations, $\omega-M_{\max }^{\text {obs }}, \omega-M_{\max }^{K-S}$ and $\omega-M_{100}$, in 29 seismogenic zones of the Iranian Plateau

\begin{tabular}{|c|c|c|c|c|c|c|c|c|c|c|c|c|c|c|c|c|}
\hline 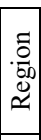 & $M c$ & $\begin{array}{c}\text { Ex- } \\
\text { treme } \\
\text { years } \\
k\end{array}$ & $M_{\max }^{\mathrm{obs}}$ & $\Lambda_{\max }^{K-S}$ & $M^{K-S}$ & $\omega$ & $\sigma \omega$ & $u$ & $\sigma u$ & $\lambda$ & $\sigma \lambda$ & $M_{100}$ & $\sigma M_{100}$ & $\begin{array}{l}\omega- \\
M_{\max }^{\mathrm{obs}}\end{array}$ & $\begin{array}{c}\omega- \\
M_{100}\end{array}$ & $\mid \begin{array}{l}\omega- \\
M_{\max }^{K-5}\end{array}$ \\
\hline 1 & 5 & 2 & & & & & 31 & & & & .28 & .64 & 0.29 & & .5 & .05 \\
\hline 2 & 5 & 2 & & & & & & & & & & & & & & \\
\hline 3 & 4.6 & 1 & & & & & & & & & 21 & & 3 & & & \\
\hline 4 & 4.4 & 2 & & 7.88 & 52 & 03 & 25 & 3.3 & & .41 & 0.23 & .45 & 0.3 & & .58 & \\
\hline 5 & 4.2 & 1 & & 7 & & & & & & & 0.24 & & 0.3 & & & \\
\hline 6 & 4 & 2 & & & & & & & & & 27 & 74 & 0.29 & & & \\
\hline 7 & 5 & 2 & & & & & & & & & 0.54 & & & & .15 & 17 \\
\hline 8 & 5 & 2 & & & & & & & & & & & .27 & & & \\
\hline 9 & & 1 & & & & & & & & & 19 & 87 & & & & \\
\hline 10 & & 2 & & & & & & & & & 46 & 22 & .3 & & & 03 \\
\hline 11 & & 2 & & & & & & & & & & & & & & \\
\hline 12 & & 4 & & & 49 & 7.32 & & .53 & & & 0.19 & 31 & 0.3 & 72 & & .27 \\
\hline 13 & 4 & 4 & & & & & & & & & 41 & 45 & 0.3 & & & \\
\hline 14 & & 1 & & & & & & & & & & & & & & \\
\hline 15 & & 2 & & 7.51 & 0.15 & 7.98 & & 4.35 & 0.19 & 0.24 & 0.22 & .85 & 0.29 & 58 & 1.13 & 0.47 \\
\hline 16 & & 2 & & & & & & & & & & & 0.28 & & & \\
\hline 17 & 5 & 1 & & & & & & & & & 0.31 & & 0.3 & & & \\
\hline 18 & & 2 & & & & 7.83 & & 2.77 & & 0.3 & 0.24 & .01 & 0.3 & 43 & 0.82 & .13 \\
\hline 19 & & 1 & & & & & & & & & & 26 & & & & \\
\hline 20 & & 1 & & & & & & & & & 0.23 & 6.04 & & & .52 & \\
\hline 21 & 5 & 2 & & & & & & & & & 0.14 & .62 & 0.29 & & & \\
\hline 22 & & 2 & & & & & & & & & & & & & & \\
\hline 23 & & 1 & & & & & & & & & 0.23 & 5.76 & 0.3 & & 32 & \\
\hline 24 & 4.8 & 2 & & 5.85 & & & & 4.19 & & 0. & 0.3 & 5.88 & 0.31 & 0.68 & & 0.43 \\
\hline 25 & 4.4 & 2 & & & & & & & & & 0.21 & & 0.3 & & 0.58 & \\
\hline 26 & 5 & 1 & & & & & & & & & 0.14 & 7.23 & 0.27 & & & \\
\hline 27 & 4.7 & 1 & & & & 6.06 & & & & 0.42 & 0.19 & 5.75 & 0.3 & 0.46 & 0.31 & 0.12 \\
\hline 28 & 4.2 & 3 & & & & & & & & & & & & & .46 & \\
\hline 29 & 4.6 & 2 & 6.6 & 7.1 & 0.41 & 1.20 & 1.9 & 4.07 & 0.44 & 0.29 & 0.26 & 6.52 & 0.3 & 0.68 & 0.76 & 0.18 \\
\hline
\end{tabular}

mum magnitude estimated by Kijko-Sellevoll method $\left(M_{\max }^{K-S}\right)$ is also evaluated and its uncertainty is listed in this table along with the values of difference $\left(\omega-M_{\max }^{K-S}\right)$. The "extreme years", listed in Table 1 have been deduced from the observations since we have rarely full samples of results with extreme years of 1 year. The cumulative probability distribution functions of 
GIII have been calculated using annual extreme magnitudes according to Eq. 3; this was followed by the assessment of the GIII estimates by using annual extremes. The Gumbel III graphs including probabilities computed for 29 regions are shown in Fig. 3.
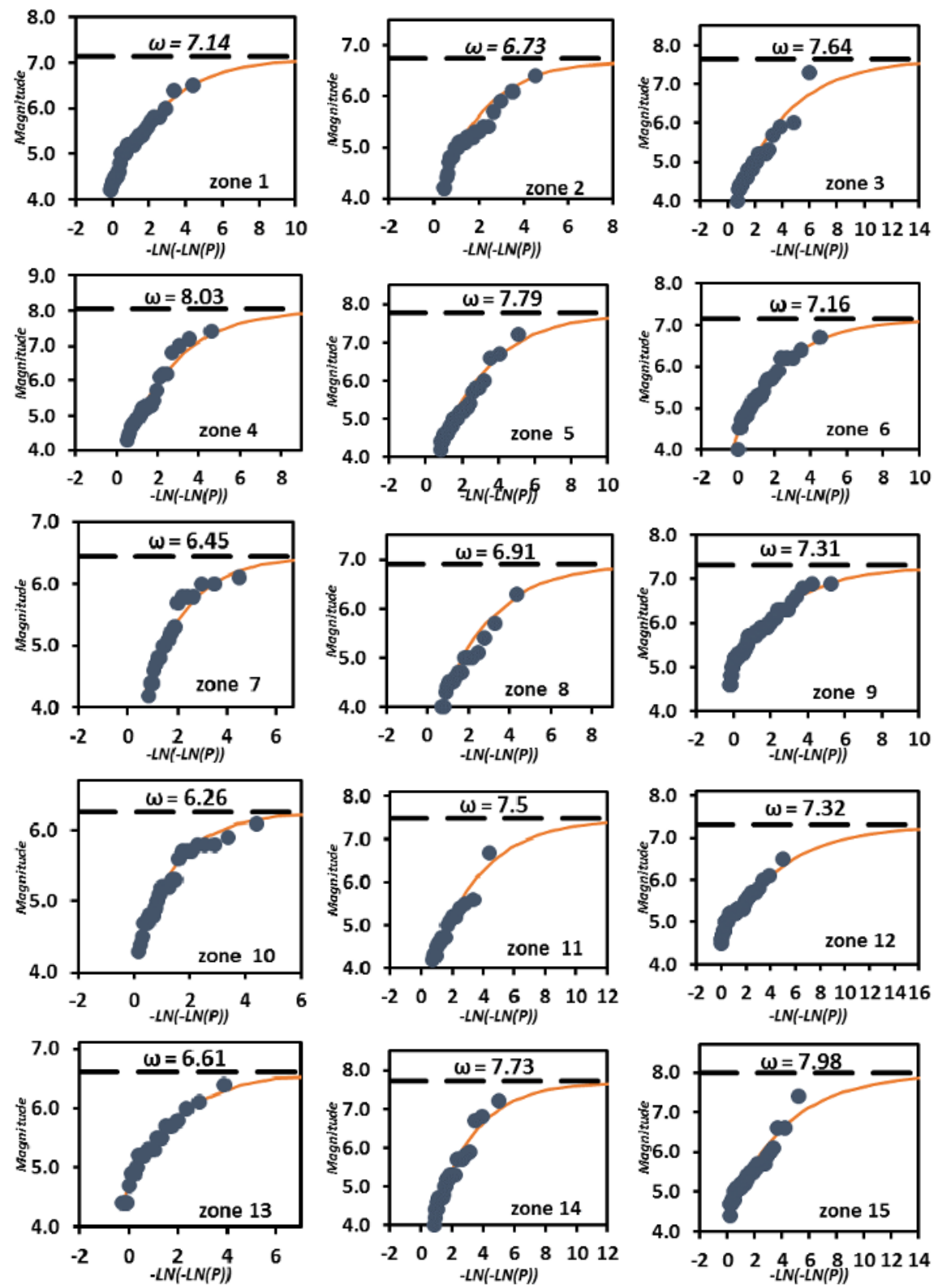

Fig. 3. Caption on next page. 

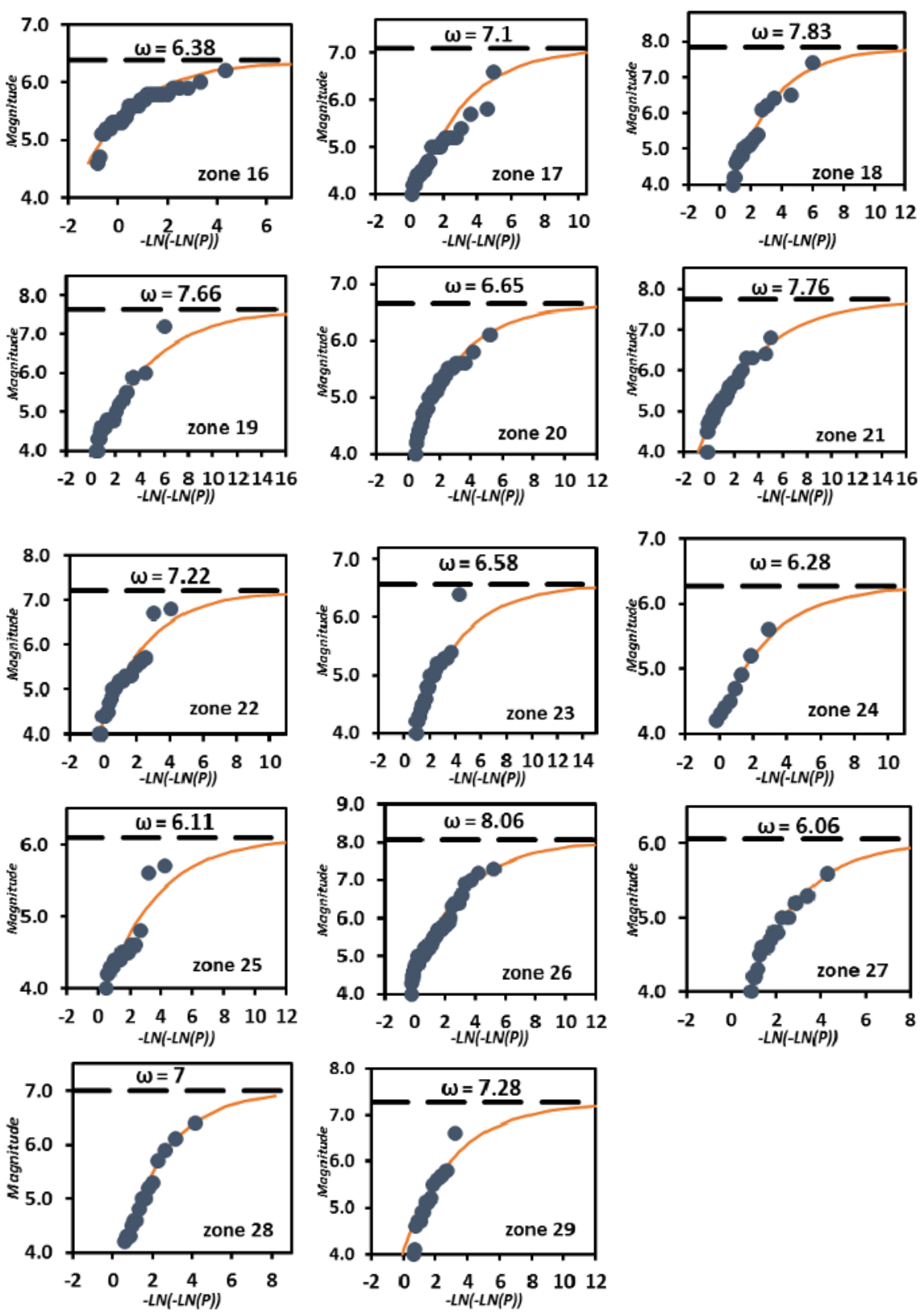

Fig. 3. Gumbel III distribution curves for 29 seismogenic zones of the Iranian Plateau. Solid curve line shows theoretical fitting of observed data (solid circles). Dash line shows the line of maximum magnitude $(\omega)$ estimated by GIII distribution. 


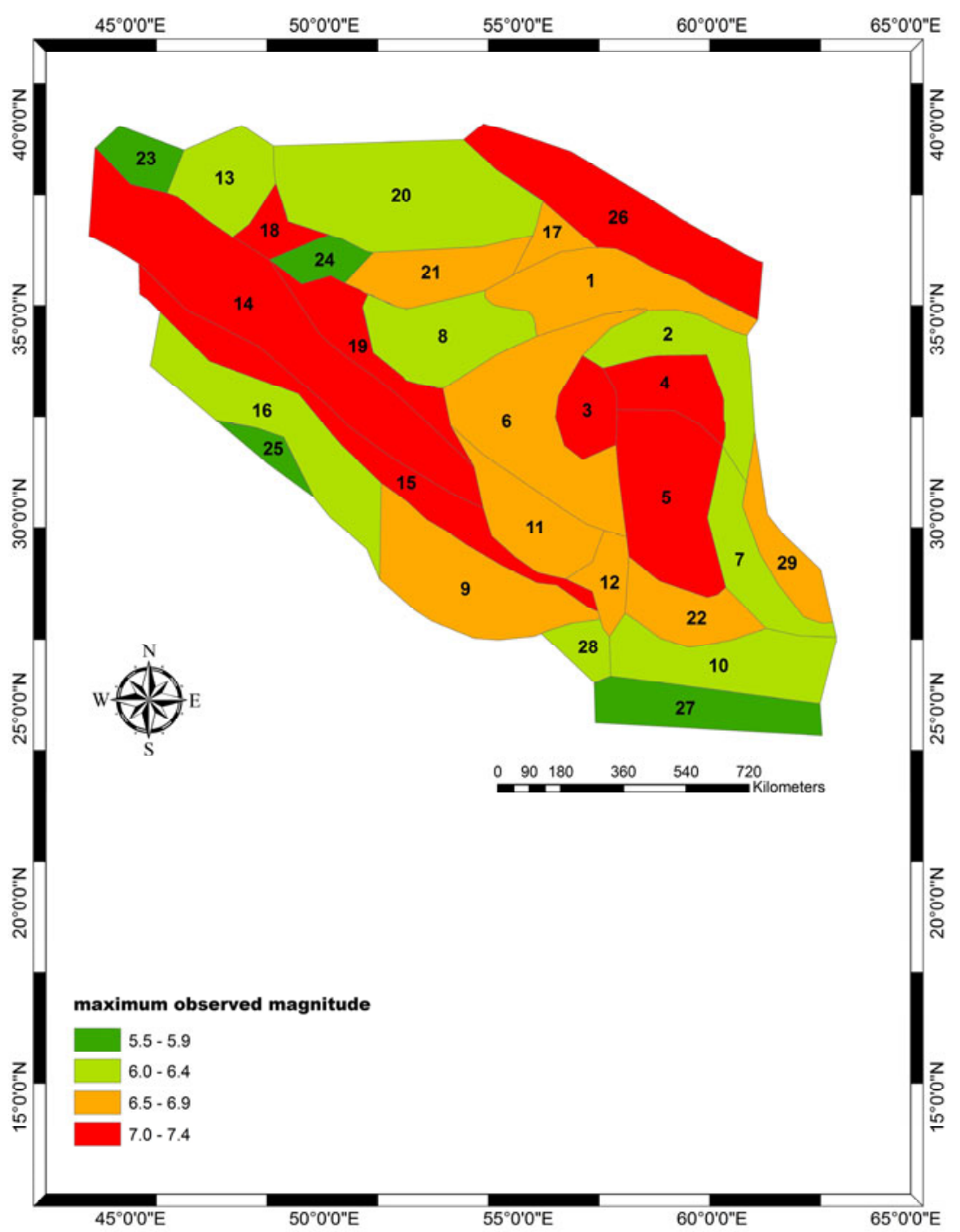

Fig. 4. The $M_{\max }^{\text {obs }}$ value in 29 seismogenic zones in the Iranian Plateau (seismogenic zones defined by Karimiparidari et al. (2011)).

Regional variability of $M_{\max }^{\text {obs }}$ and $\omega$ values for each 29 region is shown in Figs. 4 and 5. We divided $M_{\max }^{\mathrm{obs}}$ into four groups as shown by legends with different color scale in Fig. 4, namely: (i) 5.5-5.9, (ii) 6-6.4, (iii) 6.56.9 , (iv) 7-7.4, and divided $\omega$ into four groups shown by different color scale in Fig. 5, namely: (i) 6.06-6.50, (ii) 6.51-6.99, (iii) 7-7.5, (iv) 7.51-8.06. 


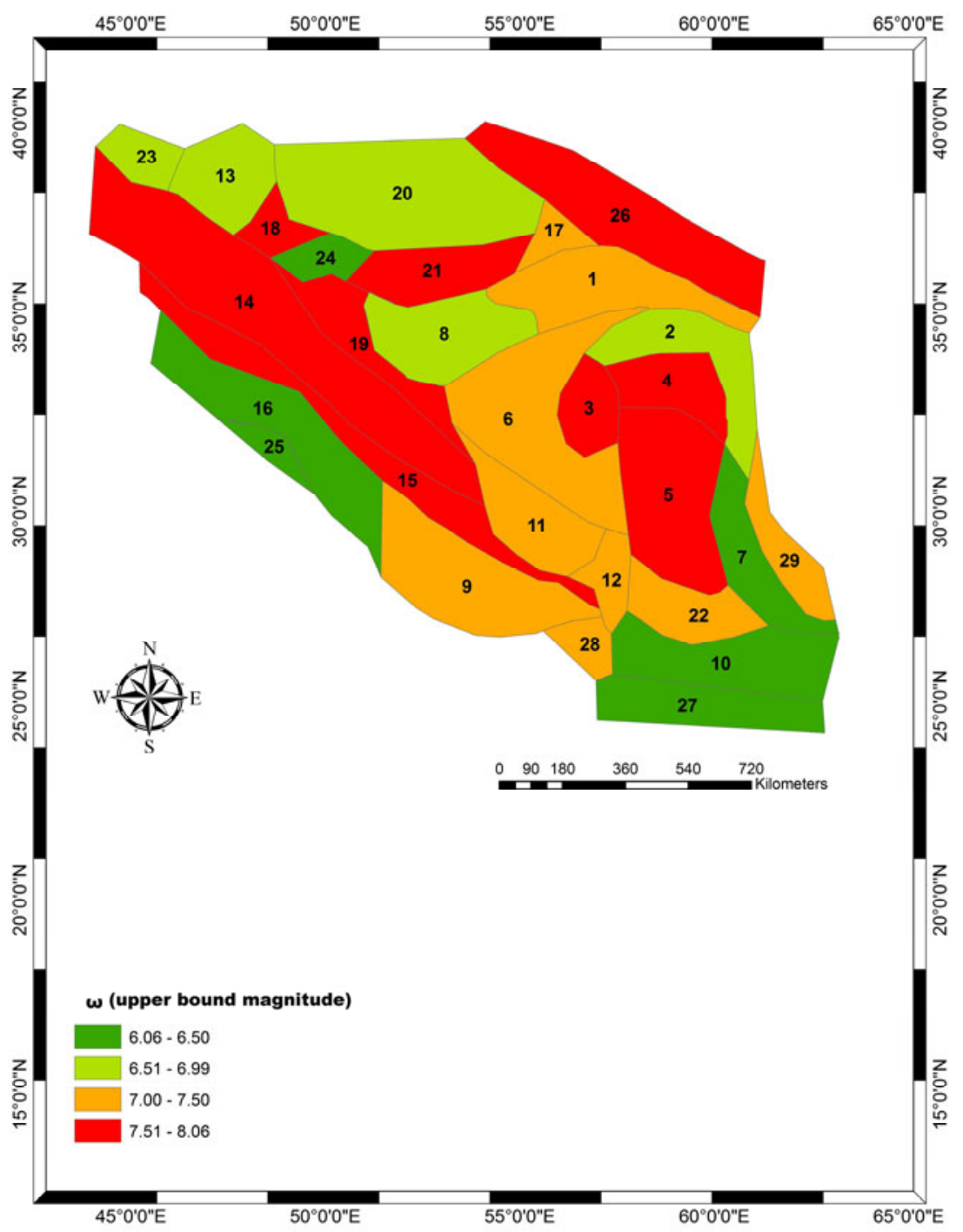

Fig. 5. The $\omega$ value from GUMBEL III in 29 seismogenic zones in the Iranian Plateau (seismogenic zones defined by Karimiparidari et al. (2011)).

The regional variation of upper bound magnitude $(\omega)$, given in Fig. 5, shows the more hazardous seismogenic zones in the examined region. It may be considered that $\omega$ value associated to a region shows maximum earthquake size which may be occur in the future and we cannot expect a larger earthquake magnitude than the $\omega$ value in this region. In the examined area, the $\omega$ values greater than 8.0 are computed in seismogenic zone 26 related to 
the main Kopeh-Dagh fault and seismogenic zone 4 related to Central and East Iran, the $\omega$ values 7.5-8 are computed in regions 15, 18, 5, 21, 14, 19, 3, and 11. These seismogenic zones are related to Central and East Iran, Kopeh-Dagh and Alborz and Azerbaijan. Regions with a high degree of mechanical homogeneity must have high $\omega$ values (Tsapanos 1990, 1997). The rocks in regions of a high degree of mechanical homogeneity can accumulate stress and strain for long time with no energy release through an earthquake. However, the spatial distribution map of $\omega$ values (Fig. 5) shows that Central and East Iran, Alborz and Azerbaijan, SE Zagros and Kopeh-Dagh are highly hazardous seismic regions in the examined area.

Nowroozi and Ahmadi (1986) evaluated that the provinces that are located southwest of the Zagros Thrust and northeast of the Arabian landmass are most likely to produce earthquakes with magnitude of six in less than a decade. However, the northern (Alborz and Azerbaijan) and northeastern (Central and East Iran and Kopeh-Dagh) provinces are each capable of producing an earthquake with a magnitude of 7.5 per century. The highest seismic hazard exists for Alborz, Kopeh-Dagh (KD), Ferdows, and Fars (SE Zagros) provinces. Mirzaei et al. $(1997,1999)$ suggested a maximum possible magnitude of no less than $M s=7.8$ in the different regions of Iran. Later Yazdani and Kowsari (2013) (using Bayesian estimation) showed results for the cutoff magnitude of 6.5 which indicate that the highest probability of seismic hazard exists in the Alborz, Kopeh-Dagh, Banndar Abbas (SE Zagros), Kerman (Central Iran), and Zagros regions. The seismic hazard is the lowest for the Esfahan-Sirjan region, the Arabian Platform, the Persian Gulf, and Kavir in Central Iran. Recently Karimiparidari et al. (2013) estimated $M_{\max }$ by Kijko and Sellevoll $(1989,1992)$ method in five major seismogenic zones using the instrumental and historical data. They calculated $M_{\max }$ in Alborz $(=7.8)$, Azerbaijan (=7.9), Central and East Iran (=7.7), Zagros Mountain Range (=7.5), and Kopeh-Dagh (=7.7).

For each seismogenic zone, the $\left(\omega-M_{\max }^{\text {obs }}\right)$ differences, as shown in Fig. 6, are spatially mapped in the 29 seismogenic zones of the examined region for four categories: (i) $0.16-0.35$, (ii) $0.36-0.49$, (iii) $0.5-0.72$, (iv) $0.73-$ 0.96 . The difference $\left(\omega-M_{\max }^{\mathrm{obs}}\right)$ is significantly higher than $(0.5 \leq)$ in more seismogenic zones which are related to Central and East Iran, Kopeh-Dagh, and Alborz and Azerbaijan. The observed low $(<0.5)$ values of the difference $\left(\omega-M_{\max }^{\text {obs }}\right)$ in the seismogenic zone which are located Zagros and Makran show that these regions have high crustal heterogeneity and the energy is being released in the form of continuous earthquakes.

The maximum expected magnitudes to be observed in the next 100 years $\left(M_{100}\right)$ are computed in the 29 regions of Iranian Plateau to test whether an earthquake as much as $\omega$ values may occur in each region. The most proba- 


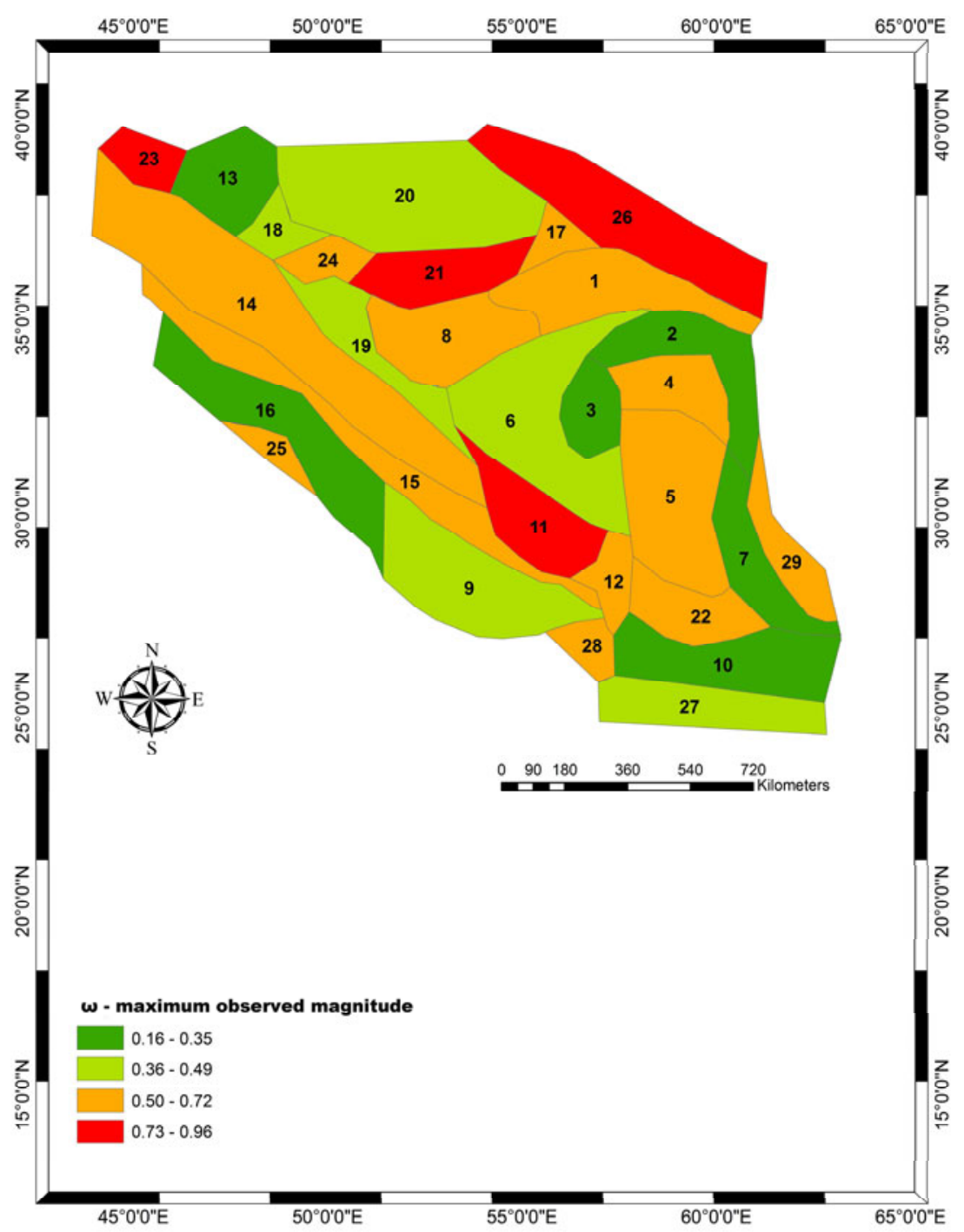

Fig. 6. Spatial distribution of $\omega-M_{\max }^{\mathrm{obs}}$ in 29 seismogenic zones in the Iranian Plateau (seismogenic zones defined by Karimiparidari et al. (2011)).

ble magnitudes in next 100 years $\left(M_{100}\right)$ are listed in Table 1, and its regional variability is shown in Fig. 7. We divided $M_{100}$ in four groups to show its geographical variation in the examined region: (i) 5.53-6, (ii) 6.01-6.50, (iii) $6.51-6.89$, (iv) $6.9-7.45$. The maximum expected magnitudes to be observed in the next 100 years is higher than 6.5 in the more seismogenic zone which are related Central and East Iran, Kopeh-Dagh, Alborz and Azerbai- 


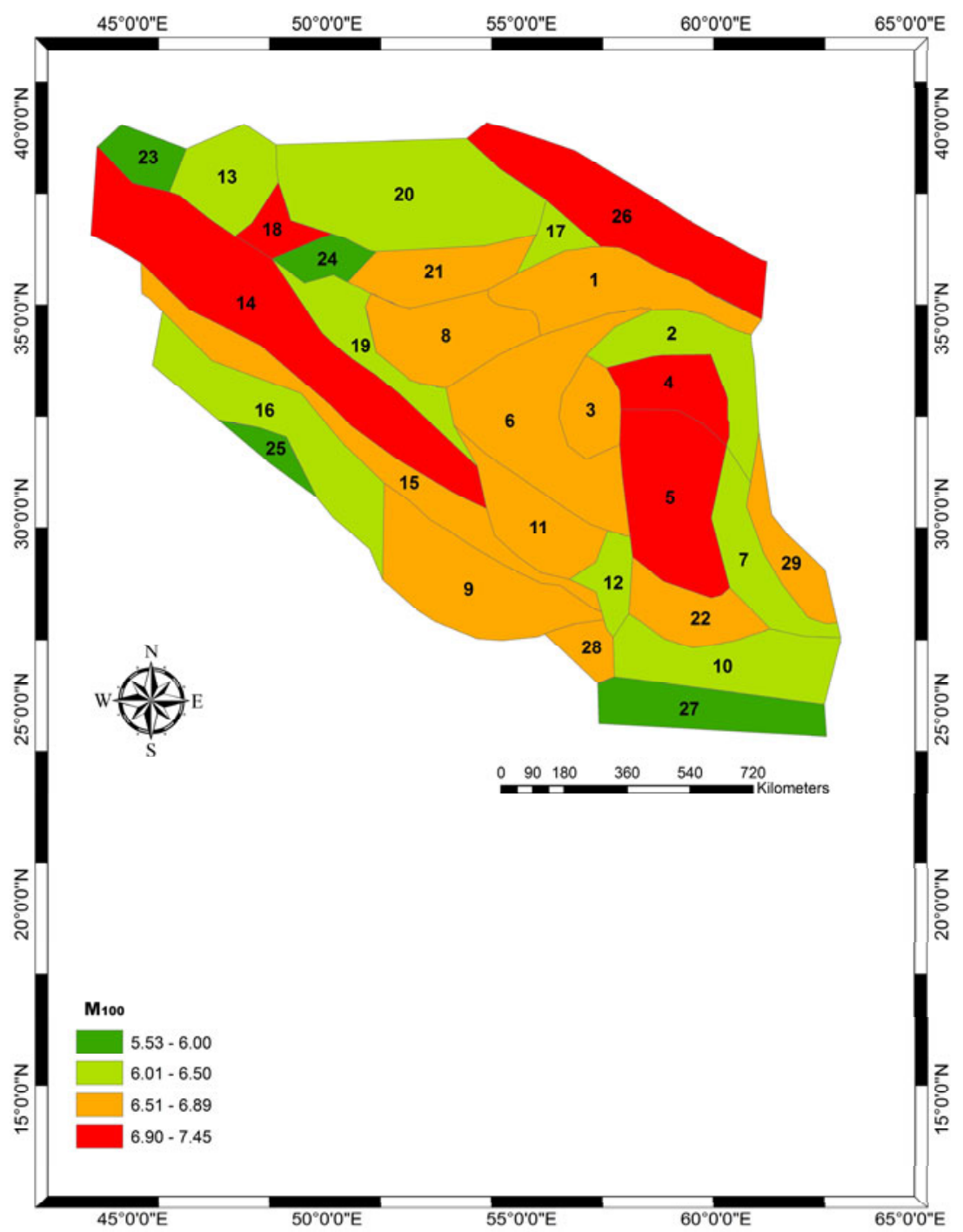

Fig. 7. Spatial distribution of $M_{100}$ in 29 seismogenic zones in the Iranian Plateau (seismogenic zones defined by Karimiparidari et al. (2011)).

jan, and SE Zagros. However, for each region the $\left(\omega-M_{100}\right)$ differences shown in Fig. 8 are spatially mapped in the 29 seismogenic zones of the examined region for four categories. It is observed that all $M_{100}$ values are lower than $\omega$ values in the respective zones. The $\left(\omega-M_{100}\right)$ differences are observed to be more than 1.0 in seismogenic zones $19,6,16,20$, and 22 (Table 1). 


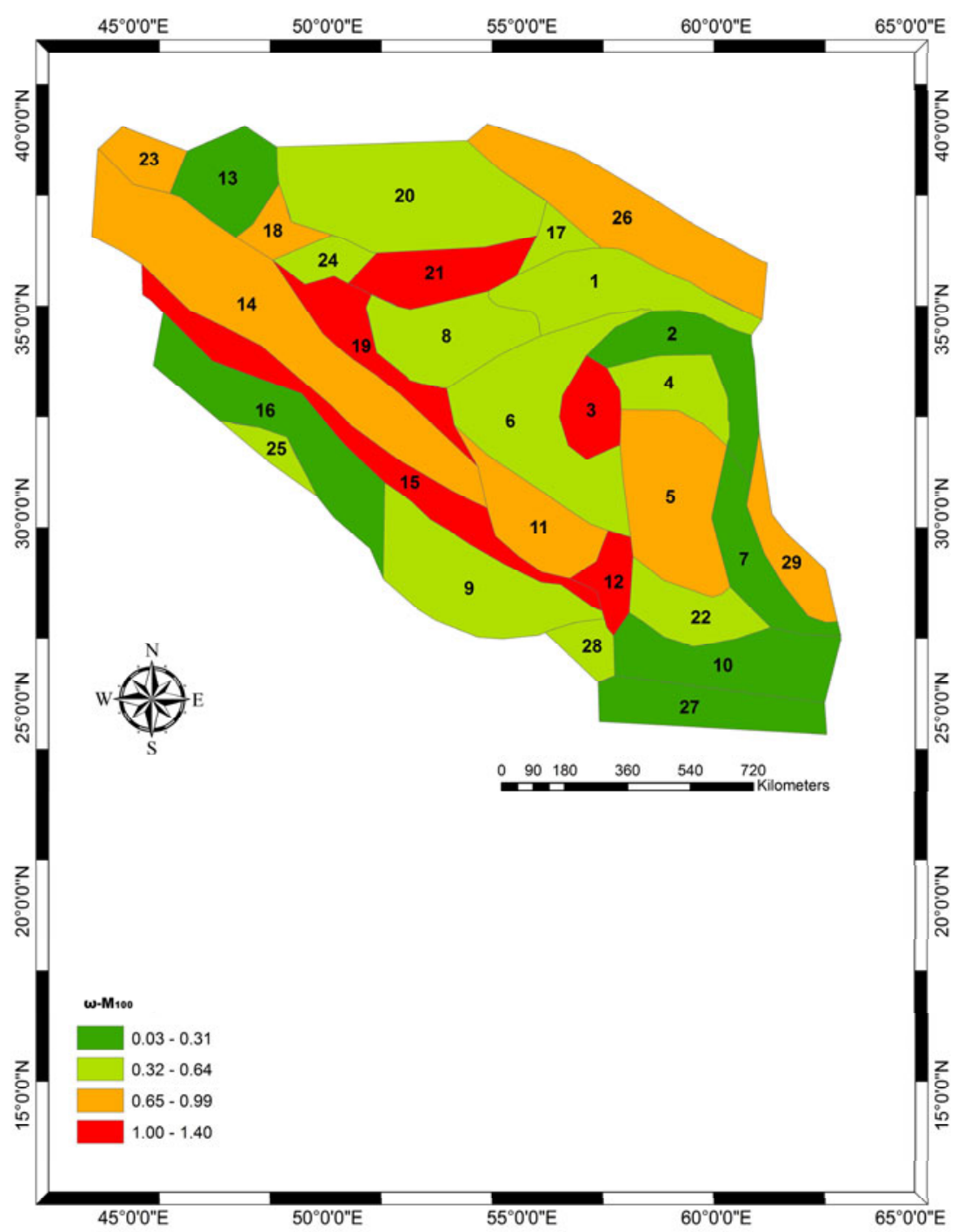

Fig. 8. Spatial distribution of $\omega-M_{100}$ in 29 seismogenic zones in the Iranian Plateau (seismogenic zones defined by Karimiparidari et al. (2011)).

We have also calculated the maximum magnitudes in the 29 seismogenic zones using maximum likelihood estimate of Kijko-Sellevoll method $\left(M_{\max }^{K-S}\right)$ using same earthquake data; the results are listed in Table 1 and shown in Fig. 9. Moreover, the values of difference $\left(\omega-M_{\max }^{K-S}\right)$ are listed in Table 1. 


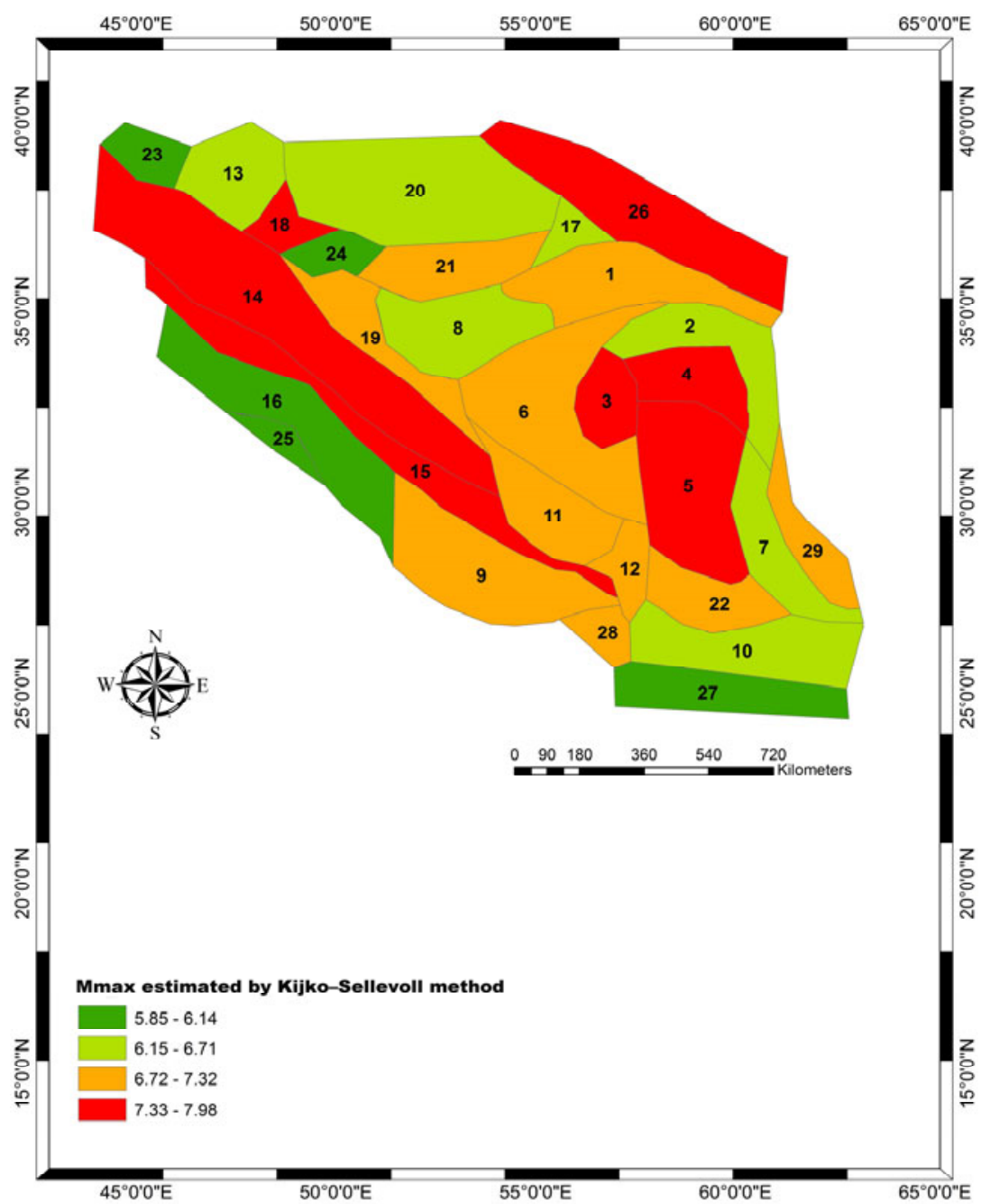

Fig. 9. Spatial distribution of maximum magnitude estimated by Kijko-Sellevoll method $\left(\omega-M_{\max }^{K-S}\right)$ in 29 seismogenic zones in the Iranian Plateau (seismogenic zones defined by Karimiparidari et al. (2011)).

A linear regression relationship has been developed between the two values of $M_{\max }$ estimated by GIII (i.e., $\omega$ ) and Kijko-Sellevoll method $\left(M_{\max }^{K-S}\right)$ (Fig. 10). The developed relation takes the form of:

$$
\omega=0.9319 M_{\max }^{K-S}+0.7198, \quad R^{20}=0.92 .
$$

It is observed that the estimated $\omega$ values for the examined area are in good agreement with the $M_{\max }^{K-S}$ for the 29 seismogenic zones. In other 


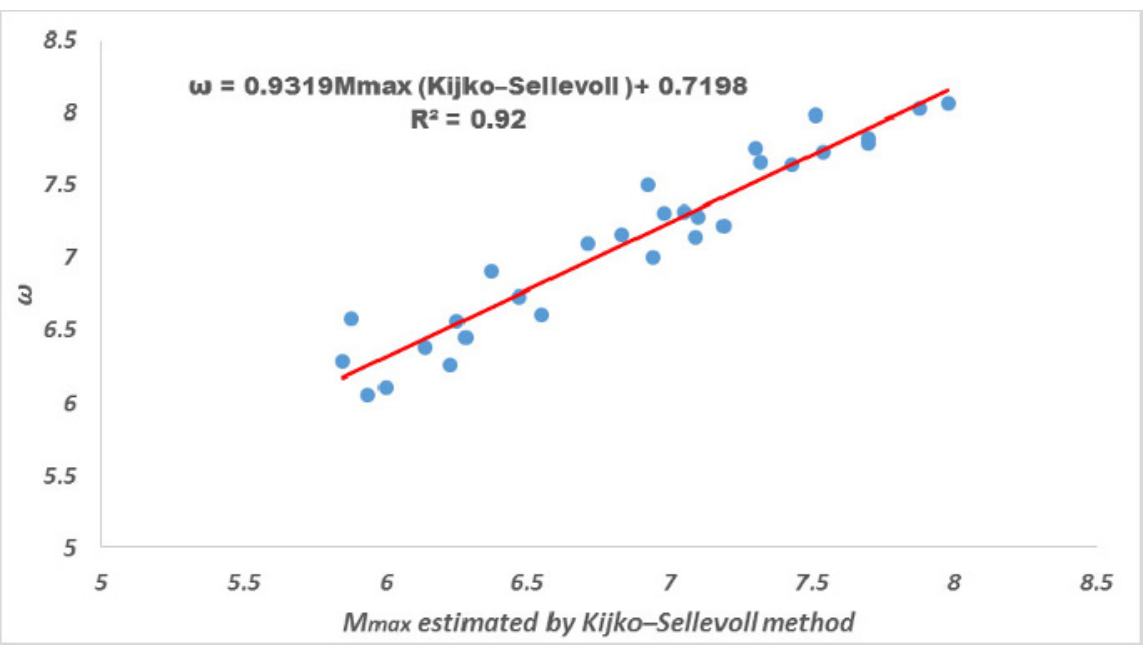

Fig. 10. Linear regression relationship between $\omega$ and $M_{\max }^{K-S}$.

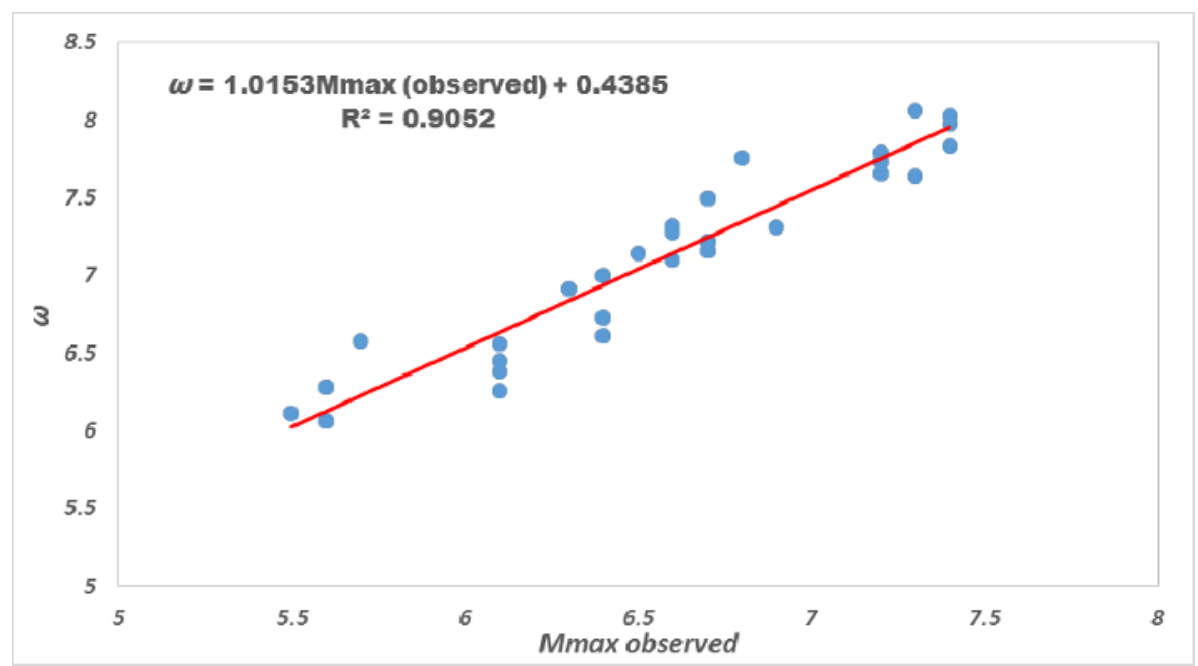

Fig. 11. Linear regression relationship between $\omega$ and $M_{\max }^{\mathrm{obs}}$.

words, there is a positive correlation between $M_{\max }$ estimated by GIII $(\omega)$ and Kijko-Sellevoll method $\left(M_{\max }^{K-S}\right)$. Also, the differences between $\omega$ and $M_{\max }^{K-S}$ vary from 0.03 to 0.7 with the average of differences is only 0.25 , suggesting both estimates are reliable and significant.

Similarly, we have made correlation between $\omega$ and maximum observed magnitude ( $\left.M_{\max }^{\mathrm{obs}}\right)$ (Fig. 11) and the regression relation takes the form: 


$$
\omega=1.0153 M_{\text {max }}^{\text {obs }}-0.4385, \quad R^{20}=0.9052 .
$$

However, we found out there is a positive correlation between maximum observed magnitude ( $M_{\max }^{\mathrm{obs}}$ ) and that estimated by method of GIII. Also it is observed that their differences vary from 0.16 to 0.96 with a mean of 0.53 , suggesting a good linear relation between these two values for the examined region. Thus, if we have the observed magnitude in any zone of the examined region, we can estimate the upper bound magnitude which can be generated by that zone.

\section{CONCLUSIONS}

From the estimated results in this study, it may be concluded that the upper bound magnitude $(\omega)$ estimated by method of GIII and maximum magnitude estimated by Kijko-Sellevoll are comparable to each other and a linear relationship exists between them. The calculated lower values of maximum magnitude by Kijko-Sellevoll method than the $\omega$ values suggest that no earthquake with a larger $\omega$ value can occur in any seismogenic zone and it is a characteristic value of any source zone. A linear relationship is also established between the maximum observed magnitude $\left(\omega-M_{\max }^{\mathrm{obs}}\right)$ and the upper bound magnitude $(\omega)$ for the examined region and it will be a benefit relation to get an idea about upper bound magnitude in other regions using the maximum observed magnitude. The difference between these two parameters $\left(\omega-M_{\max }^{\mathrm{obs}}\right)$ shows the degree of heterogeneity or homogeneity of the rocks. It is observed that more seismogenic zones which are located in Kopeh-Dagh, Central and East Iran, Alborz and Azerbaijan have high value of $\omega-M_{\max }^{\text {obs }}$. This shows that these seismogenic zones have high degree of homogeneity and the rocks in these seismogenic zones of a high degree of mechanical homogeneity can accumulate stress and strain for a long time with no energy release through an earthquake. Moreover, the value of ( $\left.\omega-M_{\max }^{\text {obs }}\right)$ is low in Zagros and Makran. So these regions have high crustal heterogeneity and energy is being released in the form of successive earthquakes.

The two important parameters estimated in this study are the upper bound magnitude $(\omega)$ and the most probable earthquake magnitude in the next 100 years $\left(M_{100}\right)$. It is estimated that the upper bound magnitudes are higher than 8.0 for region 26 related to Kopeh-Dagh and region 4 related to Central Iran. A very interesting result of this study is that the most probable earthquake magnitudes in the next 100 years $\left(M_{100}\right)$ are higher than the maximum observed magnitude in regions $24,8,16,7,27,28,1,10,2,23,13,4$, 6 , and 25 . So this reveals that in the next 100 years, these zones may experi- 
ence magnitudes of earthquakes greater than the maximum magnitude that has been observed during past 112 years (1900-2012).

Acknowledgements. We wish to thank the anonymous reviewers for their constructive reviews, which substantially improved the original manuscript. Also the authors would like to express their sincere thanks to Prof. Dr. A. Kijko for providing computer program written in Matlab.

\section{References}

Alavi, M. (1996), Tectonostratigraphic synthesis and structural style of the Alborz mountain system in northern Iran, J. Geodyn. 21, 1, 1-33, DOI: 10.1016/ 0264-3707(95)00009-7.

Allen, M.B., S.J. Vincent, G.I. Alsop, A. Ismail-Zadeh, and R. Flecker (2003), Late Cenozoic deformation in the South Caspian region: effects of a rigid basement block within a collision zone, Tectonophysics 366, 3-4, 223-239, DOI: 10.1016/S0040-1951(03)00098-2.

Ambraseys, N.N., and C.P. Melville (1982), A History of Persian Earthquakes, Cambridge University Press, Cambridge.

Båth, M. (1975), Seismicity of the Tanzania region, Tectonophysics 27, 4, 353-379, DOI: 10.1016/0040-1951(75)90004-9.

Båth, M. (1983), Earthquake frequency and energy in Greece, Tectonophysics 95, 3-4, 233-252, DOI: 10.1016/0040-1951(83)90070-7.

Bayrak, Y., S. Öztürk, H. Çinar, G.Ch. Koravos, and T.M. Tsapanos (2008), Regional variation of the $\omega$-upper bound magnitude of GIII distribution in and around Turkey: tectonic implications for earthquake hazards, Pure Appl. Geophys. 165, 7, 1367-1390, DOI: 10.1007/s00024-008-0359-z.

Berberian, M. (1976), Contribution to the seismotectonics of Iran. Part II, Geological Survey of Iran, Report No. 39.

Berberian, M. (1977), Contribution to the seismotectonics of Iran. Part III, Geological Survey of Iran, Report No. 40.

Berberian, M. (1983), The southern Caspian: A compressional depression floored by a trapped, modified oceanic crust, Can. J. Earth Sci. 20, 2, 163-183, DOI: 10.1139/e83-015.

Berberian, M. (1994), Natural hazards and the first earthquake catalogue of Iran. Vol. 1. Historical hazard in Iran prior to 1900, International Institute of Earthquake Engineering and Seismology (IIEES), Tehran, Iran, 620 pp.

Berberian, M. (1995), Master "blind" thrust faults hidden under the Zagros folds: active basement tectonics and surface morphotectonics, Tectonophysics 241, 3-4, 193-224, DOI: 10.1016/0040-1951(94)00185-C. 
Berberian, M. (1997), Seismic sources of the Transcaucasian historical earthquakes. In: D. Giardini and S. Balassanian (eds.), Historical and Prehistorical Earthquakes in the Caucasus, 233-311, Kluwer Academic Publishers.

Berberian, M. (2014), Earthquakes and Coseismic Surface Faulting on the Iranian Plateau. A Historical, Social and Physical Approach, Elsevier Publishing, Amsterdam, 776 pp.

Berberian, M., and R.S. Yeats (1999), Patterns of historical earthquake rupture in the Iranian Plateau, Bull. Seismol. Soc. Am. 89, 1, 120-139.

Berberian, M., and R.S. Yeats (2001), Contribution of archaeological data to studies of earthquake history in the Iranian Plateau, J. Struct. Geol. 23, 2-3, 563584, DOI: 10.1016/S0191-8141(00)00115-2.

Berberian, M., J.A. Jackson, M. Qorashi, M. Talebian, M. Khatib, and K. Priestley (2000), The 1994 Sefidabeh earthquakes in eastern Iran: blind thrusting and bedding-plane slip on a growing anticline, and active tectonics of the Sistan suture zone, Geophys. J. Int. 142, 2, 283-299, DOI: 10.1046/j.1365-246x. 2000.00158.x.

Burton, P.W. (1977), The application of extreme value statistics to seismic hazard assessments in the European area. In: Proc. Symp. Analysis and on Seismic Risk, 17-22 October 1977, Liblice.

Burton, P.W. (1979), Seismic risk in southern Europe through to India examined using Gumbel's third distribution of extreme values, Geophys. J. Int. 59, 2, 249-280, DOI: 10.1111/j.1365-246X.1979.tb06766.x.

Byrne, D.E., L.R. Sykes, and D.M. Davis (1992), Great thrust earthquakes and aseismic slip along the plate boundary of the Makran Subduction Zone, J. Geophys. Res. 97, B1, 449-478, DOI: 10.1029/91JB02165.

Dargahi-Noubary, G.R. (2002), The use of modern statistical theories in the assessment of earthquake hazard, with application to quiet regions of eastern North America, Soil Dyn. Earthq. Eng. 22, 5, 361-369, DOI: 10.1016/ S0267-7261(02)00027-1.

Engdahl, E.R., J.A. Jackson, S.C. Myers, E.A. Bergman, and K. Priestley (2006), Relocation and assessment of seismicity in the Iran region, Geophys. J. Int. 167, 2, 761-778, DOI: 10.1111/j.1365-246X.2006.03127.x.

Epstein, B., and C. Lomnitz (1966), A model for the occurrence of large earthquakes, Nature 211, 5052, 954-956, DOI: 10.1038/211954b0.

Field, E.H., D.D. Jackson, and J.F. Dolan (1999), A mutually consistent seismichazard source model for southern California, Bull. Seismol. Soc. Am. 89, 3, 559-578.

Gringorten, I.I. (1963), A plotting rule for extreme probabilistic paper, J. Geophys. Res. 68, 3, 813-814, DOI: 10.1029/JZ068i003p00813.

Gumbel, E.J. (1958), Statistics of Extremes, Columbia University Press, New York, $375 \mathrm{pp}$. 
Hollingsworth, J., J. Jackson, R. Walker, M.R. Gheitanchi, and M.J. Bolourchi (2006), Strike-slip faulting, rotation, and along-strike elongation in the Kopeh Dagh mountains, NE Iran, Geophys. J. Int. 166, 3, 1161-1177, DOI: 10.1111/j.1365-246X.2006.02983.x.

Hollingsworth, J., J. Jackson, J.E. Alarcon, J.J. Boomer, and M.J. Bolourchi (2007), The 4th February 1997 Bojnourd (Garmkhan) earthquake in NE Iran: Field, teleseismic, and strong-motion evidence for rupture directivity effects on a strike-slip fault, J. Earthq. Eng. 11, 2, 193-214, DOI: 10.1080/ 13632460601031078.

Jackson, J., and D. McKenzie (1984), Active tectonics of the Alpine-Himalayan Belt between western Turkey and Pakistan, Geophys. J. Int. 77, 1, 185-264, DOI: 10.1111/j.1365-246X.1984.tb01931.x.

Jackson, J., K. Priestley, M. Allen, and M. Berberian (2002), Active tectonics of the South Caspian Basin, Geophys. J. Int. 148, 2, 214-245, DOI: 10.1046/ j.1365-246X.2002.01588.x.

Kagan, Y.Y. (2002), Seismic moment distribution revisited: I. Statistical results, Geophys. J. Int. 148, 3, 520-541, DOI: 10.1046/j.1365-246x.2002.01594.x.

Kaila, K.L., and H. Narain (1971), A new approach for preparation of quantitative seismicity maps as applied to Alpide Belt-Sunda Arc and adjoining areas, Bull. Seismol. Soc. Am. 61, 5, 1275-1291.

Karimiparidari, S., M. Zaré, and H. Memarian (2011), New seismotectonic zoning map of Iran. In: Proc. 6th Int. Conf. on Seismology and Earthquake Engineering (SEE6), CD-ROM, 8 pp.

Karimiparidari, S., M. Zaré, H. Memarian, and A. Kijko (2013), Iranian earthquakes, a uniform catalog with moment magnitudes, J. Seismol. 17, 3, 897-911, DOI: $10.1007 / \mathrm{s} 10950-013-9360-9$.

Kijko, A. (1988), Maximum likelihood estimation of Gutenberg-Richter b parameter for uncertain magnitudes values, Pure Appl. Geophys. 127, 4, 573-579, DOI: $10.1007 / \mathrm{BF} 00881745$.

Kijko, A. (2004), Estimation of the maximum earthquake magnitude, $\mathrm{m}_{\max }$, Pure Appl. Geophys. 161, 8, 1655-1681, DOI: 10.1007/s00024-004-2531-4.

Kijko, A., and M.M. Dessokey (1987), Application of extreme magnitude distributions to incomplete earthquake files, Bull. Seismol. Soc. Am. 77, 4, 14291436.

Kijko, A., and M.A. Sellevoll (1989), Estimation of earthquake hazard parameters from incomplete data files. Part I: Utilization of extreme and complete catalogs with different threshold magnitudes, Bull. Seismol. Soc. Am. 79, 3, 645-654.

Kijko, A., and M.A. Sellevoll (1992), Estimation of earthquake hazard parameters from incomplete data files. Part II: Incorporation of magnitude heterogeneity, Bull. Seismol. Soc. Am. 82, 1, 120-134. 
Kijko, A., and M. Singh (2011), Statistical tools for maximum possible earthquake magnitude estimation, Acta Geophys. 59, 4, 674-700, DOI: 10.2478/s11600011-0012-6.

Knopoff, L., and Y. Kagan (1977), Analysis of the theory of extremes as applied to earthquake problems, J. Geophys. Res. 82, 36, 5647-5657, DOI: 10.1029/ JB082i036p05647.

Koravos, G.Ch., I.G. Main, T.M. Tsapanos, and R.M.W. Musson (2003), Maximum earthquake magnitudes in the Aegean area constrained by tectonic moment release rates, Geophys. J. Int. 152, 1, 94-112, DOI: 10.1046/j.1365-246X. 2003.01825.x.

Krinitzsky, E.L. (2002), How to obtain earthquake ground motions for engineering design, Eng. Geol. 65, 1, 1-16, DOI: 10.1016/S0013-7952(01)00098-9.

Makropoulos, K.C. (1978), Statistics of large earthquake magnitude and an evaluation of Greek seismicity, Ph.D. Thesis, University of Edinburgh, Edinburgh, UK, 193 pp.

Makropoulos, K.C., and P.W. Burton (1983), Seismic risk of circum-Pacific earthquakes: I. Strain energy release, Pure Appl. Geophys. 121, 2, 247-267, DOI: $10.1007 / \mathrm{BF} 02590137$.

Makropoulos, K.C., and P.W. Burton (1986), Hazan: a FORTRAN program to evaluate seismic-hazard parameters using Gumbel's theory of extreme value statistics, Comput. Geosci. 12, 1, 29-46, DOI: 10.1016/0098-3004 (86)90017-8.

Meyer, B., and K. Le Dortz (2007), Strike-slip kinematics in Central and Eastern Iran: Estimating fault slip-rates averaged over the Holocene, Tectonics 26, 5, TC5009, DOI: 10.1029/2006TC002073.

Mirzaei, N., M. Gao, and Y.T. Chen (1997), Seismicity in major seismotectonic provinces of Iran, Earthq. Res. China 11, 4, 351-361.

Mirzaei, N., M. Gao, and Y.T. Chen (1998), Seismic source regionalization for seismic zoning of Iran: major seismotectonic provinces, J. Earthq. Predic. Res. 7, 465-495.

Mirzaei, N., M. Gao, and Y.-T. Chen (1999), Delineation of potential seismic sources for seismic zoning of Iran, J. Seismol. 3, 1, 17-30, DOI: 10.1023/ A:1009737719013.

Mueller, C.S. (2010), The influence of maximum magnitude on seismic-hazard estimates in the central and eastern United States, Bull. Seismol. Soc. Am. 100, 2, 699-711, DOI: 10.1785/0120090114.

Nogol-Sadat, M.A.A. (1994), Seismotectonic map of Iran. Teritise on the geology of Iran. 1:1000 000 scale, Tehran, Iran.

Nordquist, J.M. (1945), Theory of largest values applied to earthquake magnitudes, Trans. Am. Geophys. Union 26, 1, 29-31, DOI: 10.1029/TR026i001p00029.

Nowroozi, A.A. (1976), Seismotectonic provinces of Iran, Bull. Seismol. Soc. Am. 66, 4, 1249-1276. 
Nowroozi, A.A., and G. Ahmadi (1986), Analysis of earthquake risk in Iran based on seismotectonic provinces, Tectonophysics 122, 1-2, 89-114, DOI: 10.1016/0040-1951(86)90160-5.

Pisarenko, V.F., A.A. Lyubushin, V.B. Lysenko, and T.V. Golubeva (1996), Statistical estimation of seismic hazard parameters: maximum possible magnitude and related parameters, Bull. Seismol. Soc. Am. 86, 3, 691-700.

Reiter, L. (1990), Earthquake Hazard Analysis: Issues and Insights, Columbia University Press, New York, 254 pp.

Shabanian, E., L. Siame, O. Bellier, L. Benedetti, and M.R. Abbassi (2009), Quaternary slip rates along the northeastern boundary of the Arabia-Eurasia collision zone (Kopeh Dagh Mountains, Northeast Iran), Geophys. J. Int. 178, 2 , 1055-1077, DOI: 10.1111/j.1365-246X.2009.04183.x.

Snyder, D.B., and M. Barazangi (1986), Deep crustal structure and flexure of the Arabian plate beneath the Zagros collisional mountain belt as inferred from gravity observations, Tectonics 5, 3, 361-373, DOI: 10.1029/ TC005i003p00361.

Sornette, D., L. Knopoff, Y.Y. Kagan, and C. Vanneste (1996), Rank-ordering statistics of extreme events: application to the distribution of large earthquakes, J. Geophys. Res. 101, B6, 13883-13893, DOI: 10.1029/96JB00177.

Stocklin, J. (1968), Structural history and tectonics of Iran, AAPG Bull. 52, 7, 1229 1258.

Takin, M. (1972), Iranian geology and continental drift in the Middle East, Nature 235, 5334, 147-150, DOI: 10.1038/235147a0.

Talebian, M., and J. Jackson (2004), A reappraisal of earthquake focal mechanisms and active shortening in the Zagros mountains of Iran, Geophys. J. Int. 156, 3, 506-526, DOI: 10.1111/j.1365-246X.2004.02092.x.

Tavakoli, B. (1996), Major seismotectonic provinces of Iran, Technical Report, International Institute of Earthquake Engineering and Seismology (IIEES), Tehran, Iran (in Persian).

Tavakoli, B., and M. Ghafory-Ashtiany (1999), Seismic hazard assessment of Iran, Ann. Geophys. 42, 6, 1013-1021, DOI: 10.4401/ag-3781.

Tinti, S., and F. Mulargia (1985), Effects of magnitude uncertainties on estimating the parameters in the Gutenberg-Richter frequency-magnitude law, Bull. Seismol. Soc. Am. 75, 6, 1681-1697.

Tsapanos, T.M. (1990), b-values of two tectonic parts in the circum-Pacific belt, Pure Appl. Geophys. 134, 2, 229-242, DOI: 10.1007/BF00876999.

Tsapanos, T.M. (1997), Regional variation of the $\omega$ values in the circum-Pacific belt, Pure Appl. Geophys. 150, 1, 113-120, DOI: 10.1007/s000240050066.

Tsapanos, T.M. (2003), Appraisal of seismic hazard parameters for the seismic regions of the east circum-Pacific belt inferred from a Bayesian approach, Nat. Hazards 30, 1, 59-78, DOI: 10.1023/A:1025051712052. 
Tsapanos, T.M., and P.W. Burton (1991), Seismic hazard evaluation for specific seismic regions of the world, Tectonophysics 194, 1-2, 153-169, DOI: 10.1016/0040-1951(91)90278-Z.

Tsapanos, T.M., and C.V. Christova (2003), Earthquake hazard parameters in Crete island and its surrounding area inferred from Bayes statistics: an integration of morphology of the seismically active structures and seismological data, Pure Appl. Geophys. 160, 8, 1517-1536, DOI: 10.1007/s00024-003-2358-4.

Tsapanos, T.M., O.Ch. Galanis, G.Ch. Koravos, and R.M.W. Musson (2002), A method for Bayesian estimation of the probability of the local intensity for some cities of Japan, Ann. Geophys. 45, 5, 657-671, DOI: 10.4401/ag-3528.

Tsapanos, T.M., Y. Bayrak, H. Cinar, G.Ch. Koravos, E. Bayrak, E.E. Kalogirou, A.V. Tsapanou, and G.E. Vougiouka (2014), Analysis of largest earthquakes in Turkey and its vicinity by application of the Gumbel III distribution, Acta Geophys. 62, 1, 59-82, DOI: 10.2478/s11600-013-0155-8.

Uhrhammer, R.A. (1986), Characteristics of northern and central California seismicity, Earthq. Notes 57, 1, 21 (abstract).

Vernant, P., F. Nilforoushan, J. Chéry, R. Bayer, Y. Djamour, F. Masson, H. Nankali, J.F. Ritz, M. Sedighi, and F. Tavakoli (2004), Deciphering oblique shortening of central Alborz in Iran using geodetic data, Earth Planet. Sci. Lett. 223, 1-2, 177-185, DOI: 10.1016/j.eps1.2004.04.017.

Walker, R., and J. Jackson (2004), Active tectonics and late Cenozoic strain distribution in central and eastern Iran, Tectonics 23, 5, TC5010, DOI: 10.1029/ 2003 TC001529.

Walker, R., J. Jackson, and C. Baker (2004), Active faulting and seismicity of the Dasht-e-Bayaz region, eastern Iran, Geophys. J. Int. 157, 1, 265-282, DOI: 10.1111/j.1365-2966.2004.02179.x.

Wheeler, R.L. (2009), Methods of $\mathrm{M}_{\max }$ estimation east of the Rocky Mountains, Open-File Report 2009-1018, U.S. Geological Survey, 44 pp.

Wiemer, S., and M. Wyss (2000), Minimum magnitude of completeness in earthquake catalogs: examples from Alaska, the western United States, and Japan, Bull. Seismol. Soc. Am. 90, 4, 859-869, DOI: 10.1785/0119990114.

Yadav, R.B.S., D. Shanker, S. Chopra, and A.P. Singh (2010a), An application of regional time and magnitude predictable model for long-term earthquake prediction in the vicinity of October 8, 2005 Kashmir Himalaya earthquake, Nat. Hazards 54, 3, 985-1014, DOI: 10.1007/s11069-010-9519-4.

Yadav, R.B.S., J.N. Tripathi, B.K. Rastogi, M.C. Das, and S. Chopra (2010b), Probabilistic assessment of earthquake recurrence in northeast India and adjoining regions, Pure Appl. Geophys. 167, 11, 1331-1342, DOI: 10.1007/ s00024-010-0105-1.

Yadav, R.B.S., Y. Bayrak, J.N. Tripathi, S. Chopra, A.P. Singh, and E. Bayrak (2012a), A probabilistic assessment of earthquake hazard parameters in NW Himalaya and the adjoining regions, Pure Appl. Geophys. 169, 9, 1619-1639, DOI: 10.1007/s00024-011-0434-8. 
Yadav, R.B.S., Y. Bayrak, J.N. Tripathi, S. Chopra, and E. Bayrak (2012b), Regional variation of the $\omega$-upper bound magnitude of GIII distribution in Hindukush-Pamir Himalaya and the adjacent regions: a perspective on earthquake hazard, Tectonophysics 544-545, 1-12, DOI: 10.1016/j.tecto. 2012.03.015.

Yadav, R.B.S., T.M. Tsapanos, G.Ch. Koravos, Y. Bayrak, and K.D. Devlioti (2013), Spatial mapping of earthquake hazard parameters in the Hindukush-Pamir Himalaya and adjacent regions: implication for future seismic hazard, J. Asian Earth Sci. 70-71, 115-124, DOI: 10.1016/j.jseaes.2013.03. 007.

Yazdani, A., and M. Kowsari (2013), Bayesian estimation of seismic hazards in Iran, Sci. Iran. 20, 3, 422-430, DOI: 10.1016/j.scient.2012.12.032.

Ye, H., G. Chen, and Q. Zhou (1995), Study on the intraplate potential seismic sources. In: Proc. Fifth Int. Conf. Seismic Zonation, Nice, France, Vol. 2, 1424-1430.

Yegulalp, T.M., and J.T. Kuo (1974), Statistical prediction of the occurrence of maximum magnitude earthquakes. Bull. Seismol. Soc. Am. 64, 2, 393-414.

Zare, M. (2010), Fundamental of seismic hazard analyses, Technical Report, International Institute of Earthquake Engineering and Seismology (IIEES), Tehran, Iran, 142 pp. (in Persian).

Received 1 October 2014

Received in revised form 9 July 2015

Accepted 28 July 2015 